\title{
MODEL PENYELENGGARAAN WORK-BASED LEARNING PADA PENDIDIKAN VOKASI DIPLOMA III OTOMOTIF
}

\author{
Budi Tri Siswanto \\ Pendidikan Teknik Otomotif \\ Fakultas Teknik UNY \\ budi_ts@uny.ac.id
}

\begin{abstract}
Abstrak: Model penyelenggaraan Work-Based Learning pada Pendidikan Vokasi Diploma III Otomotif. Penelitian bertujuan: (1) menemukan model penyelenggaraan work-based learning pada pendidikan vokasi program Diploma III Otomotif yang dapat meningkatkan kualitas hasil belajar; (2) mengetahui luaran penyelenggaraan work-based learning dengan model yang dikembangkan. Penelitian $R \& D$ dan eksperimen ini dilaksanakan di beberapa pusdiklat/training center berbagai APM (Agen Pemegang Merek) Otomotif di Jakarta, Karawang, Tangerang, dan Bekasi. Populasi penelitian: seluruh mahasiswa Diploma III program studi Teknik Otomotif yang melaksanakan program pengalaman lapangan/praktik industri di provinsi Daerah Istimewa Yogyakarta dan Jawa Tengah. Dua kelompok mahasiswa sebagai sampel penelitian berjumlah 100 mahasiswa ditentukan dengan teknik purposive sampling yang meliputi 3 PTN dan 3 PTS di DIY dan Jawa Tengah. Eksperimen dilaksanakan dengan rancangan faktorial $2 \times 1$. Validasi isi dilakukan dengan expert judgement dan analisis faktor dan reliabilitas butir dengan formula Alpha Cronbach dan KR-20. Data dianalisis dengan analisis deskriptif, korelasi, regresi, jalur, uji-t dengan bantuan program SPSS.17 dan Structural Equation Modeling (SEM) dengan bantuan program LISREL 8.80, taraf signifikansi 0,05. Hasil penelitian menunjukkan bahwa: (1) model WBL Rolling Terpadu cocok digunakan dalam penyelenggaraan program work-based learning Diploma III Otomotif untuk meningkatkan kualitas hasil belajar; (2) luaran (output) dari model WBL Rolling Terpadu yaitu: pengetahuan mekanik otomotif, sikap profesional, kesiapan mental kerja, dan kemandirian mahasiswa pada kelas model lebih tinggi secara signifikan dibanding kelas konvensional.
\end{abstract}

Kata Kunci: Model penyelenggaraan, Work-based learning, Pendidikan Vokasi Diploma III

\section{WORK-BASED LEARNING IMPLEMENTATION MODEL IN AUTOMOTIVE DIPLOMA III VOCATIONAL EDUCATION}

\begin{abstract}
Work-Based Learning Implementation Model in Automotive Diploma III Vocational Education. This research was aimed at: (1) finding the work-based learning implementation model in Automotive Diploma III program, (2) revealing the WBL performance outputs. $R \& D$ and experimental research was conducted at several training centers of automotive authorized dealer agencies or (APM) in Jakarta, Karawang, Tangerang, Bekasi. The population were students of Automotive Diploma III study program who were trained in industrial attachment program in Central Java and Yogyakarta Special State provinces. Two groups of 100 students as subject with purposive sampling techniques. Experiment was conducted with $2 x 1$ factorial design. Validity was examinded by expert judgment and by factors analysis. Cronbach's Alpha formula and KR-20 were used to examine the reliability. Data were analyzed by correlation, multiple regression, path, and t-test with SPSS ver.17. Goodness of Fit model were tested by Structural Equation Modeling (SEM) with LISREL 8.80. The results show that (1) WBL Rolling Terpadu model is fit to improve performance outputs in the implementation Automotive Diploma III work-based learning program, (2) outputs of WBL Rolling Terpadu model are initial automotivemechanic knowledge, professional attitude, work mentally readiness, and personality attitude. These outputs of the experimental group in student work-based learning performance are higher than that of control group.
\end{abstract}

Keyword: Model penyelenggaraan, Work-based learning, Pendidikan Vokasi Diploma III 


\section{PENDAHULUAN}

Pengembangan pembelajaran dalam penyelenggaraan pendidikan vokasi harus terus dilakukan oleh para pengelolanya agar kualitas lulusannya sesuai tuntutan pasar kerja.Tantangan dunia kerja dengan kompetensi kerja yang makin tinggi seiring kemajuan teknologi dan dinamika tempat kerja menuntut institusi pendidikan vokasi mampu mengantisipasi dan menghadapi perubahan yang terjadi dengan memanfaat-kan berbagai kapabilitas yang ada.Berbagai sinyalemen tentang kualitas pendidikan menjadi latar belakang permasalahan penyelenggaraan pendidikan vokasi Diploma III Otomotif dengan pendekatan Work-Based Learning (WBL) atau Pengajaran dan Pembelajaran Berbasis Tempat Kerja (PBTK). WBL adalah pendekatan pembelajaran yang memanfaatkan tempat kerja untuk menstrukturkan pengalaman-pengalaman yang didapat di tempat kerja berkontribusi pada sosial, akademik, dan pengembangan karir pembelajar dan menjadi suplemen dalam kegiatan pembelajaran.Pengalaman belajar di tempat kerja diaplikasikan, diperhalus, diperluas dalam pembelajaran baik di kampus maupun di tempat kerja. Dengan WBL, pembelajar mengembangkan sikap (attitude), pengetahuan (knowledge), keteram-pilan (skill), pencerahan (insight), perilaku (behavior), kebiasaan (habits), dan pergaulan (associations) dari pengalamanpengalaman kedua tempat dan memungkinkan terjadi pembelajaran yang terkait dengan aktivitas bekerja nyata (real-life work activities) (Lynch \& Harnish, 1998).

Kualitas hasil pendidikan vokasi Diploma III Otomotif baik dari segi proses maupun produk sangat dipengaruhi oleh pendekatan pembelajaran yang digunakan dalam menyelenggarakan pendidikan vokasi. Penyelenggaraan pendidikan vokasi tidak bisa tanpa kerjasama antara institusi pendidikan dengan dunia usaha dan dunia industri. Teoriteori experiential learning, context teaching and learning, dan work-based learning menjadi sangat relevan dalam penyelenggaraan pendidikan vokasi. Diperlukan pengembangan model penyelenggaraan pendidikan vokasi dengan berbagai teori tersebut untuk meningkatkan kualitas hasil pembelajaran yang pada akhirnya mempengaruhi kualitas hasil belajar dan kualitas lulusan.

Hasil-hasil penelitian mutakhir menyimpulkan bahwa pemanfaatan Pendekatan Pembelajaran Berbasis Tempat Kerja (PBTK) atau Work-Based Learning (WBL) dalam pendidikan memiliki pengaruh positif dalam prestasi (achievement), motivasi (motivation), dan kelanjutan pendidikan (continuing education) (Bailey \& Merrit, 1997). Riset dan studi evaluasi pada WBL menunjukkan adanya korelasi antara luaran (outputs) dan dampak (outcomes) lulusan dengan struktur pembelajaran yang sekolah dan industri berikan dalam pengalaman di tempat kerja. Ketika tujuan program, kurikulum dan pengalaman berbasis tempat kerja dirancang dan diaplikasikan disertai dukungan staf yang memadai dan dievaluasi dengan benar, maka program itu akan berdampak positif (Lynch \& Harnish, 1998; Fallow \& Weller, 2000; Braham $\&$ Pickering, 2007; Garnett, 2008).

Peran program Diploma III Otomotif yang menyiapkan tenaga-tenaga pelaksana dengan kualitas lulusan sesuai dengan pasar kerja diteliti dengan mengembangkan model penyelenggaraan pembelajaran berbasis tempat kerja dalam konteks kemitraan dengan industri untuk melihat 
perannya meningkatkan kualitas hasil belajar dan kualitas lulusan meliputi: (1) menemukan model penyelenggaraan work-based learning dalam pendidikan vokasi program Diploma III otomotif, (2) mengetahui luaran (output) penyelenggaraan work-based learning dengan model yang dikembangkan terhadap aspek-aspek kualitas hasil belajar.

\section{Pembelajaran Berbasis Tempat Kerja}

Pembelajaran berbasis tempat kerja atau WorkBased Learning (WBL) digunakan sebagai terminologi di berbagai negara untuk programprogram pada sekolah atau perguruan tinggi untuk memperoleh pengalaman dari dunia kerja (WBL Guide, 2002) dan untuk para remaja agar siap dalam transisi dari sekolah ke dunia kerja untuk belajar realitas dunia kerja/pekerjaan dan menjadi siap untuk membuat pilihan yang tepat dalam pekerjaan (Paris \& Mason, 1995). "Work-based learning is any training that relates directly to the requirements of the job on offer in your organization" (Glass, Higgin, \& McGregor, 2002). Medhat (2008 : 8) mendefinisikan program WBL sebagai " $a$ process for recognising, creating, and applying knowledge through, for, and at work which forms part (credits) or all of a higher education qualification". Sedangkan Raelin (2008) menyatakan bahwa WBL merupakan pembelajaran aksi (action learning) yang tidak dapat dilepaskan dari konteks pembelajaran organisasi (organizational learning) maupun organisasi yang belajar (learning organization).

WBL menjadi tren dalam pendidikan, karena mempengaruhi kepuasan pembelajar dan meningkatkan peran tutor dalam pembelajaran (Woltering, Herrler, Spitzer, \& Spreckelsen, 2009). Pembelajaran dapat diperluas dengan peralatan/lingkungan yang realistik dan didukung model-model pembelajaran yang luas seperti pembelajaran terkondisi, asosiatif, sistemik, simulatif, dan konstruktivistik (Sharpe, 2006). Gray (2001) menyatakan WBL adalah pembelajaran pada tingkat perguruan tinggi meliputi pembelajaran untuk kerja (misalnya penempatan kerja), pembelajaran pada tempat kerja (misal program in-house training), dan pembelajaran melalui kerja (misalnya terkait kerja terakreditasi oleh perguruan tinggi/dihargai sebagai sks misal pelaksanaan program $c o-o p$ ).

\section{Model Work-Based Learning}

Berbagai bentuk/model WBL antara lain : apprenticeship opportunities, career mentorship, cooperative work experience, credit for prior learning (CPL), internship, job shadowing, practicum, school-based enterpreunership, service learning, teacher externship, tech-prep, vocational student organizations, volunteer service, worksite field trip (Iseek, 2008). Menurut WBL Guide (2002), BL adalah koneksi yang direncanakan dan disupervisi dari pengalamanpengalaman kelas dengan harapan dan realitas tempat kerja. Model work-based learning yang merupakan kontinum mulai dari ceramah di kelas (classroom lecture) sampai penempatan kompetitif (competitive employ-ment). Proses berupa siklus dari classroom lecture - informal interview - industry tour - job visit - entry level work experience - on-the-job (OTJ) training approved apprenticeship program - competitive employement.

Model penyelenggaraan work-based learning, adalah model program WBL yang sistem penyelenggaraannya sudah baku, kelengkapan sarana pelatihan sudah memenuhi persyaratan standar minimum untuk melatih kompetensi, instruktur dan pembimbing lapangan 
tersedia, organisasi sumber daya manusianya baik, situasi lingkungan dan keselamatan kerjanya aman dan memadai, dan sarana pendukung lain untuk pembelajaran di tempat kerja lengkap. Semua terpenuhi pada pusdiklat/training center di berbagai industry otomotif yang dipakai sebagi mitra kerjasmaa uji coba. Dengan demikian model penyelenggaraan WBL seperti ini dapat dipakai sebagai contoh atau acuan bagi program penyelenggara WBL yang lain.

\section{Model WBL Rolling Terpadu}

Penyelenggaraan Work-Based Learning adalah penerapan model, perencanaan, pelaksanaan, pengawasan (monitoring) \& supervisi, dan evaluasi program pembelajaran berbasis dunia kerja yang dilakukan manajemen pengelola pendidikan vokasi Diploma III otomotif pada mata kuliah lapangan yang bertujuan memberikan pengalaman lapangan/industri (industrial attachment) dengan mitra kerja dunia industri dan dunia kerja.

Model Penyelenggaraan WBL Rolling Terpadu merupakan pengembang-an model penyelenggaraan praktik industri yang sudah ada. Perbaikan-perbaikan yang ada antara lain: (1) durasi pelaksanaan pengalaman diperpanjang. Selama ini durasi adalah 3 SKS lapangan atau 1,5 bulan atau ekivalen 256 jam menjadi 3 bulan $(90$ hari kalender) di 3 tempat; (2) dilaksanakan secara kelompok dengan menempatkan di asrama/mess dengan tujuan ada kegiatan kebersamaan dan efisiensi tempat, waktu, dan melatih kedisiplinan dan kerjasama tim; (3) dilakukan rolling, kelompok mahasiswa memperoleh pengalaman di tiga tempat yang berbeda agar memperoleh pengalaman yang lebih lengkap dalam spektrum bidang otomotif, disamping dapat memahami berbagai corporate culture yang lebih baik dalam proses refleksi, generalisasi-abstraksi, dan transfer dalam belajar eksperiensial dengan pengulangan /penambahan pengalaman di tiga tempat industri yang berbeda; (4) pelaksanaannya terpadu, yakni dimungkinkannya ada proses pemberian materi teori pada masing-masing lokasi yang diakui sebagai kredit (SKS). Pemberi materi adalah instruktur yang punya kualifikasi tertentu sesuai sprektrum industri. Materi ini disesuaikan dengan karakteristik industri. Model Hipotetik WBL Rolling Terpadu didapatkan berdasarkan masukan teknis dengan disesuaikan dengan kondisi beberapa APM yang meliputi: program diklat tahunan, target, fasilitas, instruktur dan lain-lain disempurnakan menjadi model Final WBL Rolling Terpadu melalui tahapan uji coba di lapangan.

\section{Penelitian Yang Sudah Dilakukan}

Telah banyak penelitian work-based learning dilakukan. Bragg (1995), Bailey \& Merritt (1993), Andrew A Rezin \& N. L. McCaslin (2001), dan Mallika Modrakee (2005). Rezin \& McCaslin menemukan bahwa di kalangan lulusan program diploma/tech-prep otomotif di Ohio tahun 1993-1994, model pemagangan secara signifikan amat menentukan dalam penyelenggaraan pendidikan vokasi, keberhasilan pekerjaan di industri, dan kepuasan lulusan. Mallika Modrakee menyimpulkan program WBL memiliki potensi untuk mengatasi berbagai masalah dalam pengembangan karir. Selanjutnya, WBL menentukan dalam penyelenggaraan pilihan bagi peserta WBL. 


\section{Kerangka berpikir}

Dalam konteks penyelenggaraan pendidikan vokasi Diploma III Otomotif dengan pendekatan work-based learning, faktor-faktor yang menentukan kualitas hasil belajar WBL selain kualitas pembelajaran adalah faktor situasional yang meliputi variabel kinerja manajemen pengelola, budaya organisasi mahasiswa, dan model penyelenggaraan work-based learning. Berdasarkan uraian diatas, kerangka berpikir atau hubungan antar variabel penelitian yang terlibat dapat digambarkan sebagai berikut:

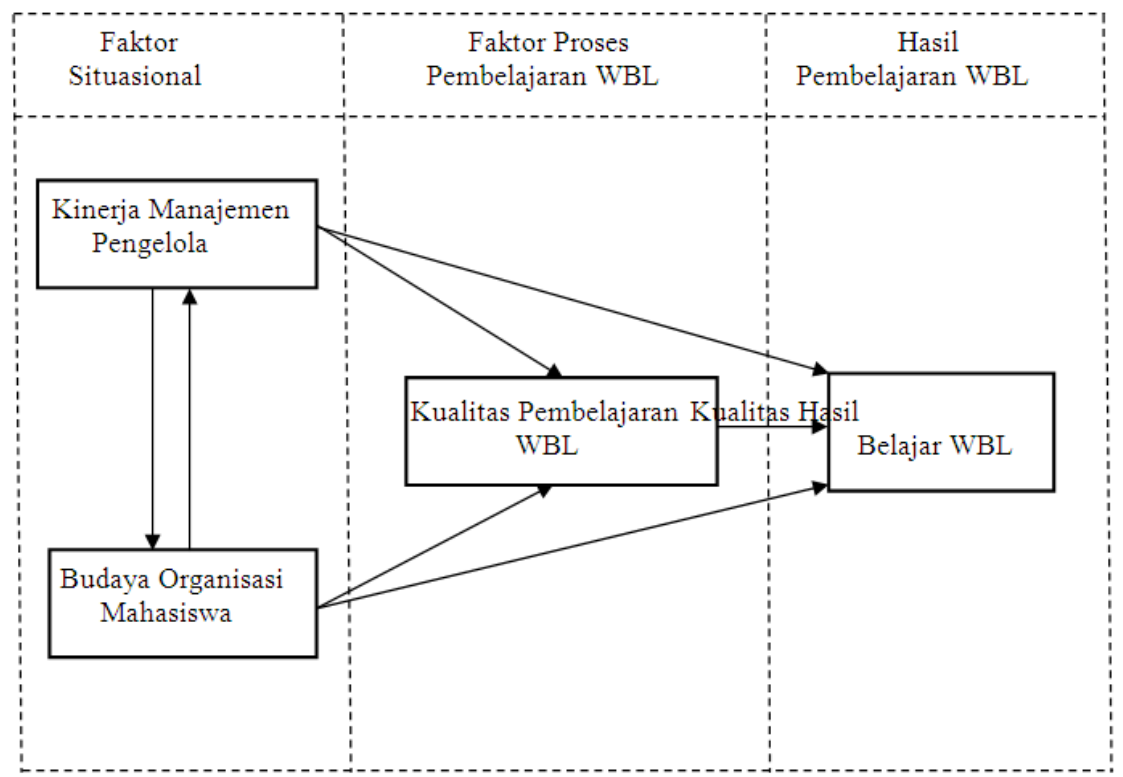

Gambar 1. Kerangka Berpikir Determinasi Kualitas Hasil Belajar WBL

\section{Hipotesis dan Pertanyaan Penelitian}

Hipotesis Mayor: Model Work-Based Learning Rolling Terpadu berpengaruh secara signifikan terhadap kualitas hasil belajar.

a. Sejauhmana efektivitas Model Work-Based Learning Rolling Terpadu untuk meningkatkan kualitas hasil belajar WBL pada mahasiswa Diploma III Otomotif?

b. Apa saja luaran (outputs) aspek kualitas hasil belajar WBL dengan model yang dikembangkan?

c. Seberapa tinggi luaran (outputs) aspek kualitas hasil belajar pada penyele-nggaraan WBL Rolling Terpadu yang meliputi: pengetahuan mekanik otomotif pemula,

\section{METODE PENELITIAN}

Metode yang digunakan dalam penelitian ini adalah model penelitian dan pengembangan atau Research and Development (R\&D) (Borg \& Gall, 1983:772) dan dilanjutkan eksperimen. Model pengembangan dalam penelitian ini melalui tahap model konseptual, model teoretik, model hipotetik, dan model final. Pengembangan model pada penelitian ini disebut sebagai Model WBL Rolling Terpadu atau WBL RoTer dengan kegiatan FGD (Focus Group Discussion), teknik Delphi, dan eksperimen. Metode pengembangan dalam penelitian ini merujuk pada model tahap R\&D yang direkomendasikan Borg \& Gall (1989) maupun Plomp (1997). 
Uji kecocokan model dengan teknik variabel sebab/eksogenous terhadap variabel Struktural Equation Modelling (SEM) dengan kriteria indek goodness of fit. Uji coba produk dilakukan dengan tujuan untuk mendapatkan informasi apakah model tersebut lebih efektif dari pada konvensional. Desain ujicoba adalah Randomizedpretest-postest control group design (desain eksperimen dengan kelompok ekperimen \& kontrol acak). Model struktural sebagai salah satu teknik analisis uji kecocokan dalam penelitian ini digunakan untuk mengetahui terikat/endogenous (Jöreskog \& Sörbom, 1996:11). Muatan faktor standar (standardized factor loading) dari variabel teramati ditetapkan $\geq 0.3$ (Borden \& Abbot, 2009:459) dan dari Tvalues nilainya $\geq 1,96$ (Wijanto, 2008:137). Model Hipotetik Penyelengaraan WBL Rolling Terpadu pada pendidikan vokasi DIII Otomotif dan tahapan pengembangan dapat digambarkan pada gambar 1 dan gambar 2: pengaruh langsung dan tidak langsung dari

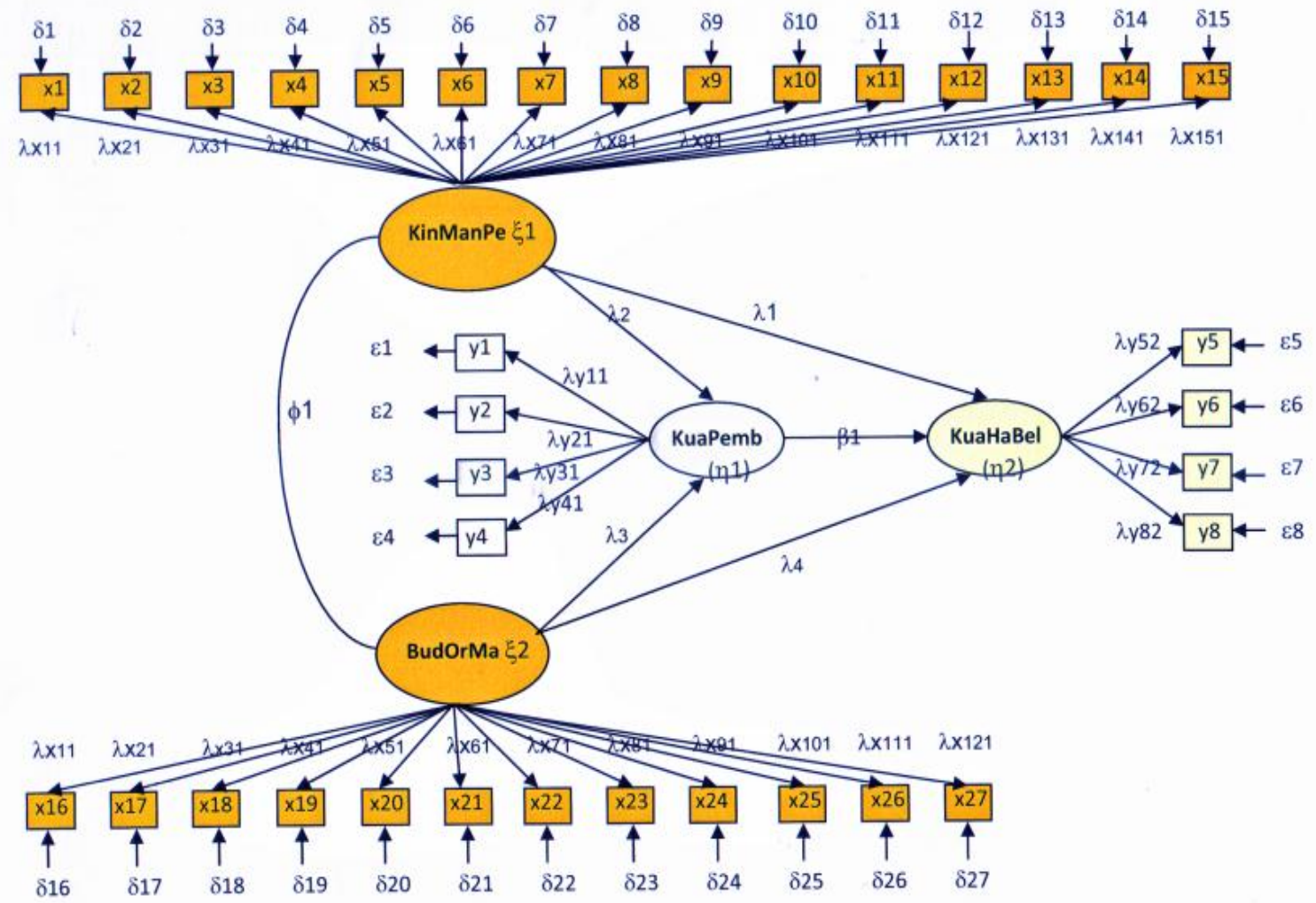

Gambar 2. Model Hipotetik antar variabel dan manifest pada

Penyelengaraan WBL Rolling Terpadu pada pendidikan vokasi DIII Otomotif

\section{Keterangan gambar:}

\begin{tabular}{|c|c|}
\hline & $\left.\mathrm{x}_{3}, \mathrm{x}_{4}, \mathrm{x}_{5}, \mathrm{x}_{6}, \mathrm{x}_{7}, \mathrm{x}_{8}, \mathrm{x}_{9}, \mathrm{x}_{10}, \mathrm{x}_{11}, \mathrm{x}_{12}, \mathrm{x}_{13,}, \mathrm{x}_{14}, \mathrm{x}_{15}\right)$ \\
\hline $2(\mathrm{~K}$ & $\begin{aligned}= & \text { Budaya organisasi mahasiswa } \\
& \left(\mathrm{x}_{16}, \mathrm{x}_{17}, \mathrm{x}_{18}, \mathrm{x}_{19}, \mathrm{x}_{20}, \mathrm{x}_{21}, \mathrm{x}_{22}, \mathrm{x}_{23}, \mathrm{x}_{24}, \mathrm{x}_{25}, \mathrm{x}_{26}, \mathrm{x}_{27}\right)\end{aligned}$ \\
\hline & $=$ Kualitas pembelajaran WBL $\left(\mathrm{y}_{1}, \mathrm{y}_{2}, \mathrm{y}_{3}, \mathrm{y}_{4}\right)$ \\
\hline & $=$ Kualitas hasil belajar WBL $\left(\mathrm{y}_{5}, \mathrm{y}_{6}, \mathrm{y}_{7}, \mathrm{y}_{8}\right)$ \\
\hline
\end{tabular}


Subyek uji coba untuk analisis efektivitas kerja model 50 mahasiswa eksperimen peserta program WBL RoTer dan 50 mahasiswa kontrol peserta program PI/PL/PKL termasuk cadangan experiment mortality 5\%. Teknik sampling secara acak. Sampel kelompok eksperimen dan kontrol merepresentasikan populasi mahasiswa D III Otomotif di wilayah DIY \& Jawa Tengah meliputi 3 penyelenggara PTN (UNY Yogyakarta, UNS Surakarta, UNNES Semarang) dan 3 penyelenggara PTS (Politeknik Muhammadiyah Yogyakarta, Politeknik Pratama, Solo dan UM Magelang). Penelitian ini dilakukan di Pusdiklat/Training Center di beberapa Agen Pemegang Merek (APM) di Jakarta, Karawang, Tangerang dan Bekasi dengan menempatkan sampel di asrama dan lokasi praktik pengalaman lapangan masing-masing APM kemudian di rolling. Penelitian ini dilakukan dalam waktu 7 bulan. Tiga bulan (01 Januari - 08 April 2010) untuk uji coba terbatas dan empat bulan (01 Juli 29 Oktober 2010) untuk Uji Coba Model. Data semua variabel diambil dengan inventori dan diolah dengan bantuan program komputer SPSS.17.

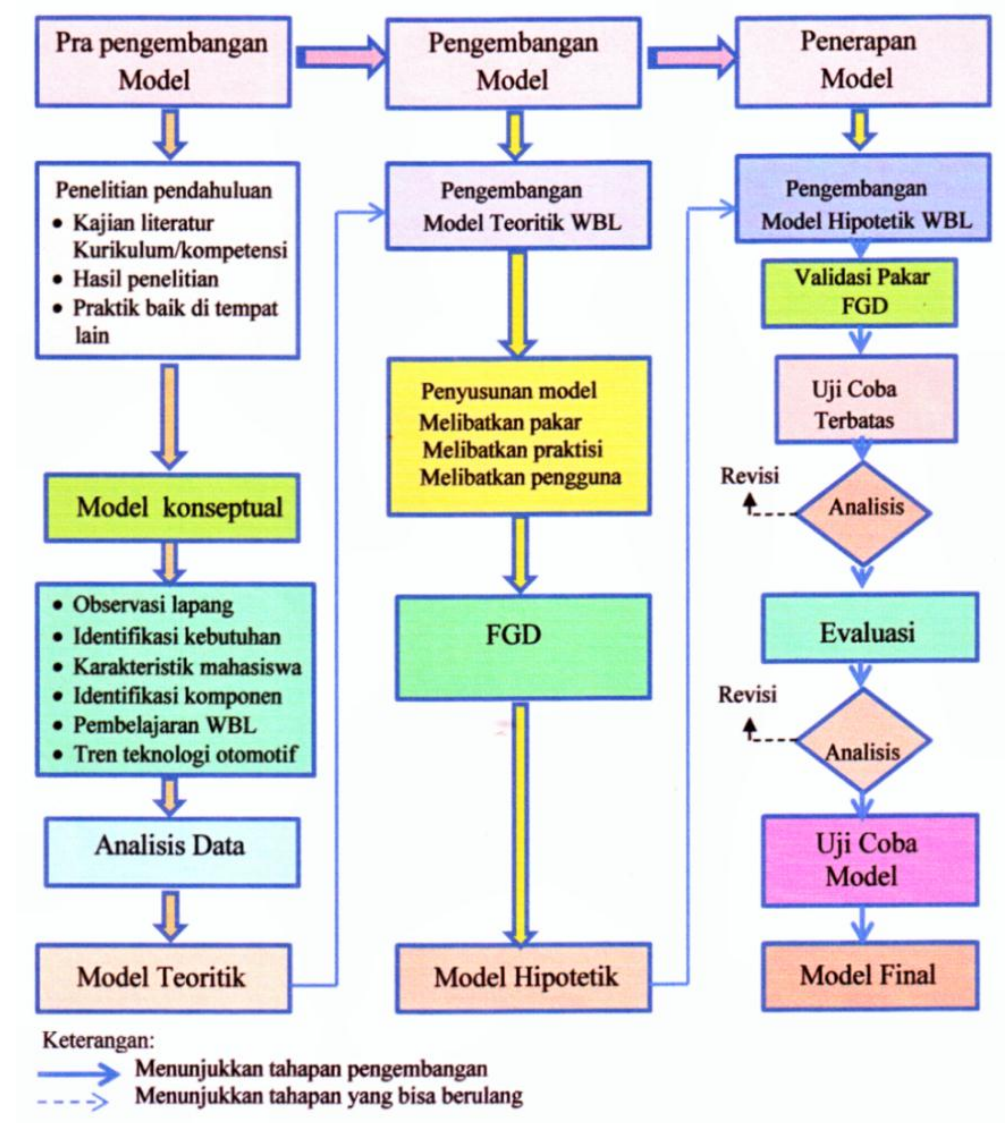

Gambar 3. Prosedur pengembangan model WBL Rolling Terpadu (diadaptasi dari Plomp)

\section{HASIL PENELITIAN DAN PEMBAHASAN}

Analisis SEM digunakan untuk mengetahui pengaruh variabel laten eksogenous: kinerja manajemen pengelola, budaya organisasi mahasiswa terhadap variabel laten endogenous: kualitas pembelajaran WBL, dan kualitas hasil pembelajaran WBL dengan bantuan program software komputer LISREL 8.8. Sebagaimana halnya model yang baik (fit) adalah secara keseluruhan (overall fit) dari instrumen dilakukan 
dengan mengkonsultasikan dengan ukuran goodness of fit index. Indikator untuk menilai model fit antara lain didasarkan pada indikator: (1) Root Mean Square Error of Aproximation (RMSEA) $\leq 0.08$ menunjukkan goodand fit; (2) p-value $\geq 0.05$; (3) Goodness of Fit Indices (GFI) $\geq 0.90 \& 0.80 \leq$ GFI, 0.90 marginal fit; dan (5) Comparative Fit Index (CFI) $\geq 0.90$, Normed Fit Index (NFI) $\geq 0.90$ (Jöreskog \& Sörbom, 1993; Solimun, 2002:80; Imam Ghozali, 2008; Wijanto, 2008).

Tahap penelitian, yaitu: (1) validasi model hipotetik, (2) uji coba keterterapan model,dan (3) uji luaran (outputs) kualitas hasil belajar WBL RoTer. Tahap pertama, validasi model "hipotetik" adalah menguji kecocokan model dengan SEM yang terdiri dari kegiatan: (1) uji efektivitas model, (2) observasi kecenderungan perubahan kualitas hasil belajar para peserta WBL.Tahap kedua, menguji hubungan antar variabel dengan uji regresi sederhana dan ganda.Tahap ketiga, menguji luaran kualitas hasil belajar WBL RoTer.

\section{Uji Efektifitas Model}

Hasil pengujian model dengan bantuan program software computer LISREL 8.80 menunjukkan nilai Goodness of Fit Index data uji coba $(\mathrm{N}=100)$ untuk semua variabel fit. Out put pengujian menunjukkan nilai Koefisie Chi Square sebesar 0.07 , perolehan $\mathrm{p}>0,05$ yang menunjukkan bahwa data empirik yang diperoleh memiliki persamaan dengan teori yang telah dibangun berdasar SEM. Artinya model mendapat dukungan secara empirik atau model cocok (fit). Hasil GOF pada parameter lainnya ditunjukkan pada tabel berikut:

Tabel 1. Hasil Goodness of Fit Index pada 3 observasi

\begin{tabular}{|c|c|c|c|c|c|c|}
\hline \multirow{2}{*}{ No } & \multirow{2}{*}{ Ukuran GOF } & \multirow{2}{*}{ Cut of Value } & \multicolumn{2}{|c|}{ Hasil Estimasi Amatan } & \multirow{2}{*}{ Keterangan } \\
\cline { 4 - 7 } & & $\mathbf{1}$ & $\mathbf{2}$ & $\mathbf{3}$ & \\
\hline 1 & Kai kuadrat $(\mathrm{p})$ & $\begin{array}{c}\text { Kecil } \\
(\mathrm{p}>0.05)\end{array}$ & $\begin{array}{c}970,13 \\
(\mathrm{P}=0.15)\end{array}$ & $\begin{array}{c}1.124,20 \\
(\mathrm{P}=0.23)\end{array}$ & $\begin{array}{c}1.667,35 \\
(\mathrm{P}=0.31)\end{array}$ & Terpenuhi \\
\hline 2 & RMSEA & $\leq 0.08(\mathrm{~min})$ & 0.07 & 0.06 & 0.06 & Terpenuhi \\
\hline 3 & NFI & $\geq 0.90$ & 0.94 & 0.95 & 0.97 & Baik \\
\hline 4 & CFI & $\geq 0.09$ & 0.40 & 0.37 & 0.20 & Terpenuhi \\
\hline 5 & PGFI & $>0.06$ & 0.48 & 0.56 & 0.66 & Terpenuhi \\
\hline 6 & GFI & $\geq 0.90$ & 0.98 & 0.97 & 0.94 & Baik \\
\hline 7 & AGFI & $\geq 0.80$ & 0.94 & 0.90 & 0.91 & Baik \\
\hline
\end{tabular}

Hasil pengujian ini menunjukkan bahwa model yang dihipotesiskan cocok dengan data yang diperoleh dari data lapangan secara konsisten pada amatan 1, 2, dan 3. Juga dari hasil regresi ganda tiga faktor, koefisien determinan $\left(\mathrm{R}^{2}\right)$ dari ketiga variabel bebas $\mathrm{KMP}\left(\mathrm{X}_{1}\right), \mathrm{KPB}$ $\left(\mathrm{X}_{2}\right)$, dan BOM $\left(\mathrm{X}_{3}\right)$ terhadap variabel $\mathrm{KHB}(\mathrm{Y})$ adalah $0,250,0,119$, dan 0,255 . Dengan demikian variabel kualitas hasil belajar WBL dapat terjelaskan oleh ketiga variabel bebas sebesar 20,0\% untuk amatan1, 11,9\% untuk amatan 2, dan 25,5\% untuk amatan 3 .

Sedangkan dari hasil uji-t antar kelompok dan antar amatan disampaikan pada tabel 2, terbukti berbeda secara signifikan bahwa model penyelenggaraan WBL Rolling Terpadu meningkatkan kualitas pembelajaran WBL. 
Tabel 2. Rangkuman hasil Uji-t semua variabel antar kelompok (signifikansi 0,05)

\begin{tabular}{|c|c|c|c|c|c|c|c|c|c|}
\hline \multirow{2}{*}{ Variabel } & \multicolumn{3}{|c|}{ Observasi 1} & \multicolumn{3}{|c|}{ Observasi 2} & \multicolumn{3}{|c|}{ Observasi 3} \\
\hline & $\mathbf{t}$ & Sig. & Ket & $\mathbf{t}$ & Sig. & Ket & $\mathbf{t}$ & Sig. & Ket \\
\hline $\begin{array}{l}\text { Kinerja Manajemen } \\
\text { Pengelola (X1) }\end{array}$ & .077 & .046 & Signifikan & .324 & .001 & Signifikan & .024 & .000 & Signifikan \\
\hline $\begin{array}{l}\text { Budaya Organisasi } \\
\text { Mahasiswa (X2) }\end{array}$ & 2.843 & .105 & $\begin{array}{c}\text { Tidak } \\
\text { signifikan }\end{array}$ & 4.940 & .004 & Signifikan & 2.675 & .000 & Signifikan \\
\hline $\begin{array}{l}\text { Kualitas Pem- } \\
\text { belajaran WBL (X3) }\end{array}$ & .253 & .013 & Signifikan & 1.974 & .006 & Signifikan & .175 & .000 & Signifikan \\
\hline $\begin{array}{l}\text { Kualitas Hasil } \\
\text { Belajar WBL (Y) }\end{array}$ & 3.152 & .093 & $\begin{array}{c}\text { Tidak } \\
\text { signifikan }\end{array}$ & 6.307 & .275 & $\begin{array}{c}\text { Tidak } \\
\text { signifikan }\end{array}$ & .693 & .000 & Signifikan \\
\hline $\begin{array}{l}\text { Pengetahuan } \\
\text { Mekanik Otomotif } \\
\text { Pemula (Y1) }\end{array}$ & .757 & .700 & $\begin{array}{c}\text { Tidak } \\
\text { signifikan }\end{array}$ & .002 & .885 & $\begin{array}{c}\text { Tidak } \\
\text { signifikan }\end{array}$ & 2.027 & .000 & Signifikan \\
\hline $\begin{array}{l}\text { Sikap Profesional } \\
\text { Mahasiswa (Y2) }\end{array}$ & .364 & .748 & $\begin{array}{c}\text { Tidak } \\
\text { signifikan }\end{array}$ & .743 & .469 & $\begin{array}{c}\text { Tidak } \\
\text { signifikan }\end{array}$ & .010 & .001 & Signifikan \\
\hline $\begin{array}{l}\text { Kesiapan Mental } \\
\text { Kerja (Y3) }\end{array}$ & 1.112 & .767 & $\begin{array}{c}\text { Tidak } \\
\text { signifikan }\end{array}$ & 4.558 & .146 & $\begin{array}{c}\text { Tidak } \\
\text { signifikan }\end{array}$ & 1.623 & .000 & Signifikan \\
\hline $\begin{array}{l}\text { Kemandiri-an } \\
\text { Mahasiswa (Y4) }\end{array}$ & 2.262 & .036 & Signifikan & 2.606 & .088 & $\begin{array}{c}\text { Tidak } \\
\text { signifikan }\end{array}$ & .983 & .000 & Signifikan \\
\hline
\end{tabular}

a. Efektivitas Model Work-Based Learning Rolling Terpadu untuk meningkatkan kualitas pembelajaran praktik pengalaman industri pada mahasiswa Diploma III Otomotif dapat disimpulkan bahwa Model WBL Rolling Terpadu memiliki efektivitas pada tingkat tinggi yakni: (1) rerata 3,6 dari skala 4 pada intensitas, (2) rerata 3,7 dari skala 4 pada efisiensi, (3) rerata 3,7 dari skala 4 pada sistematik, (4) rerata 3,8 dari skala 4 pada praktis, (5) rerata 3,5 dari skala 4 pada produktif.

b. Luaran (outputs) aspek kualitas hasil belajar pada penyelenggaraan WBL Rolling Terpadu yang meliputi: pengetahuan mekanik otomotif pemula, sikap profesional mahasiswa, kesiapan mental kerja, dan kemandirian mahasiswa pada akhir observasi: (1) rerata pengetahuan mekanik otomotif pemula tinggi (24,84-signifikan), (2) sikap profesional mahasiswa tinggi (45,03-signifikan), (3) kesiapan mental kerja sangat tinggi (85,59-signifikan), dan kemandirian mahasiswa sangat tinggi $(96,35$ signifikan).

Besarnya pengaruh langsung dan tak langsung sebagai berikut:

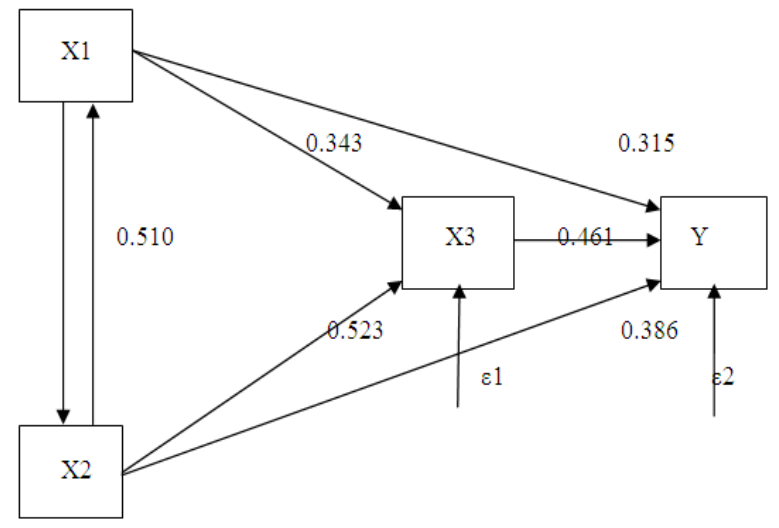

Keterangan:

X1 : Kinerja Manajemen Pengelola (menurut mahasiswa)

X2 : Budaya Organisasi Mahasiswa

X3 : Kualitas Pembelajaran WBL

Y : Kualitas Hasil Pembelajaran WBL 
Hasil perhitungan hubungan kausal empirik antar variable :

1. Pengaruh langsung

$$
\begin{aligned}
& \mathrm{p}_{\mathrm{x} 3 \mathrm{x} 1}=0,343 \\
& \mathrm{p}_{\mathrm{x} 3 \mathrm{x} 2}=0,523 \\
& \mathrm{p}_{\mathrm{yx} 1}=0,315 \\
& \mathrm{p}_{\mathrm{yx} 2}=0,386 \\
& \mathrm{p}_{\mathrm{yx} 3}=0,461
\end{aligned}
$$

\section{Pengaruh tak langsung}

$$
\begin{aligned}
& \mathrm{X} 1-\mathrm{Y} \text { melalui } \mathrm{X} 3=\mathrm{px} 3 \mathrm{x} 1 \cdot \mathrm{pyx} 3=0,343 . \\
& 0,461=0,157 \\
& \mathrm{X} 2-\mathrm{Y} \text { melalui } \mathrm{X} 3=\mathrm{p} \times 3 \mathrm{x}_{2} \cdot \mathrm{pyx} 3=0,523 . \\
& 0,461=0,241
\end{aligned}
$$

\section{PEMBAHASAN}

Hasil pengujian hipotesis mayor, menunjukkan bahwa model penyelenggaraan WBL Rolling Terpadu memiliki pengaruh signifikan terhadap kualitas hasil belajar WBL yang meliputi aspek: pengetahuan mekanik otomotif pemula, sikap profesional, kesiapan mental kerja, maupun kemandirian mahasiswa. Keempat variabel aspek kualitas hasil belajar di atas pada kelompok eksperimen memiliki rerata yang lebih tinggi secara signifikan dibanding kelompok kontrol yang melaksanakan program pengalaman lapangan dengan model magang konvensional.

Ini sangat penting, karena selama ini, aspek pengalaman lapangan/industri lebih menekankan pada kognitif dan ketrampilan saja.Aspek afektif sikap profesional, kesiapan mental kerja, dan kemandirian dengan model ini juga signifikan meningkat. Hal yang sama ditunjukkan pada variabel lain yang mempengaruhi kualitas hasil belajar WBL. Kinerja manajemen pengelola (menurut persepsi mahasiswa), kualitas pembelajaran WBL, dan budaya organisasi mahasiswa juga lebih tinggi secara signifikan pada kelompok eksperimen dibanding kelompok kontrol. Hasil ini menunjukkan bahwa model WBL Rolling Terpadu efektif untuk meningkatkan kualitas hasil belajar. Ini sejalan dengan berbagai penelitian tentang penerapan program work-based learning di beberapa negara dan beberapa sekolah atau perguruan tinggi (Bragg, 1995; Rezin \& McCaslin, 2001; Mallika Modrakee, 2005).

Tanggapan manajemen pengelola tentang penyelenggaraan WBL dengan model Rolling Terpadu juga dalam kategori tinggi. Ini menunjukkan tingkat keberterimaan model untuk diselenggarakan dalam lingkungan pusdiklat Itraining center mereka. Termasuk persepsi mereka tentang konsep model Rolling Terpadu, program WBL yang seharusnya, dan soft skill yang dapat dilatihkan dalam model ini. Apakah luaran yang lain selain yang sudah diteliti juga tinggi? Misal kompetensi praktik mekanik otomotif, sikap terhadap profesi mekanik, sikap terhadap karir bidang otomotif dan lainlain.Penelitian lebih lanjut dapat dilakukan untuk mengungkap aspek-aspek tersebut di atas.

Dengan penambahan durasi pengalaman industri menjadi tiga bulan dan adanya rolling di tiga lokasi, menjadikan kualitas pembelajaran lebih baik, persepsi mahasiswa terhadap kinerja pengelola lebih tinggi, dan budaya organisasi mahasiswa lebih baik dan akhirnya kualitas hasil belajar mahasiswa juga lebih tinggi. Mahasiswa memperoleh bimbingan baik secara individu maupun kelompok lebih intensif, disamping dengan proses mengalami, mahasiswa memiliki pengalaman ("experience") yang lebih panjang dan banyak sehingga kesempatan melakukan refleksi, generalisasi dan abstraksi, dan transfer dalam pembelajaran eksperiensial lebih dalam. Pengalaman belajar yang disediakan dalam 
model ini sangat lengkap antara lain adanya kebersamaan dalam kehidupan sehari-hari (di asrama/mess), bimbingan mentor (individu/kelompok), pembelajaran mandiri (membuat program diklat produktif yang disupervisi pembimbing industri) dan fasilitas diklat yang memadai (di pusdiklat/training center) dengan situasi yang sangat kondusif (lingkungan tempat kerja, disiplin waktu, kerjasama tim, dan target belajar yang jelas).

Hasil penelitian ini, akan sangat baik jika dikembangkan pada APM yang memiliki kapasitas pusdiklat yang lebih lengkap misalnya asrama yang lebih besar daya tampungnya dan displin asrama yang ketat, program CSR yang teratur, kualitas SDM yang terstandar lebih baik, fasilitas yang lebih lengkap. Meskipun model ini secara esensial bisa juga berlaku dan diselenggarakan oleh beberapa bengkel APM di daerah yang tidak memiliki asrama atau mess.Umumnya bengkel-bengkel APM di daerah sudah menerapkan standar layanan purna jual seperti penjualan, servis, maupun spare part yang sesuai dengan standar di bengkel pusat.Tidak ada perbedaan yang mencolok antara standar bengkel/layanan purna jual atau fasilitas antara bengkel di pusat atau di daerah.Disamping juga kontrol kualitas mekanik yang standar dan berjenjang, prosedur standar operasi yang baik, jaringan yang luas dan corporate culture yang sudah mapan.

Meskipun model Rolling Terpadu dilaksanakan pada tiga spektrum otomotif teknik kendaraan ringan, teknik oto bodi, dan teknik ototronika atau belum seluruh spektrum otomotif tercakup, namun peneliti yakin dapat dilaksanakan pula dalam dua spektrum lain yakni teknik kendaraan ringan dan teknik alat berat. Dengan partisipasi berbagai APM dalam spektrum yang luas, model WBL Rolling Terpadu menjadi sangat memungkinkan untuk dilaksanakan dan kombinasi kompetensi yang akan dicapai mahasiswa menjadi lengkap, jika APM yang terlibat memiliki spektrum yang bervariasi. Kombinasi tiga spektrum dari lima spektrum otomotif yang ada tentu sangat menarik untuk dilaksanakan dengan berbagai kombinasi pernyelenggaraan.

Model ini terbukti efektif untuk pembelajaran mata kuliah pengalaman industri (PI/KP/PK /PKL) dengan bentuk kerjasama dan komitmen yang tinggi dari berbagai APM di wilayah Jakarta, Karawang, Tangerang, dan Bekasi. Saran pemanfaatan: (a) menerapkan model ini secara luas baik pada wilayah kota besar (sebagaimana setting penelitian) maupun kota-kota lain dengan memanfaatkan main dealer, local training, atauauthorized sales service yang dimiliki di beberapa daerah yang pada umumnya juga menyelenggarakan pelatihan regular dengan spektrum otomotif yang lebih luas. (b) capaian model penyelenggaraan WBL Rolling Terpadu bersifat terminal destination bukan final destination, artinya model ini masih perlu langkah pengembangan dan pengujian lain dengan melibatkan pusdiklat/training center APM dengan spektrum industri otomotif yang lebih luas dan daerah yang lebih luwes; (c) perlunya penelitian sejenis pada bidang lain mengenai penyelenggaraan workbased learning pada pendidikan vokasi.

Model final WBL RoTer dapat dilihat pada gambar 3 dan gambar 4 . 


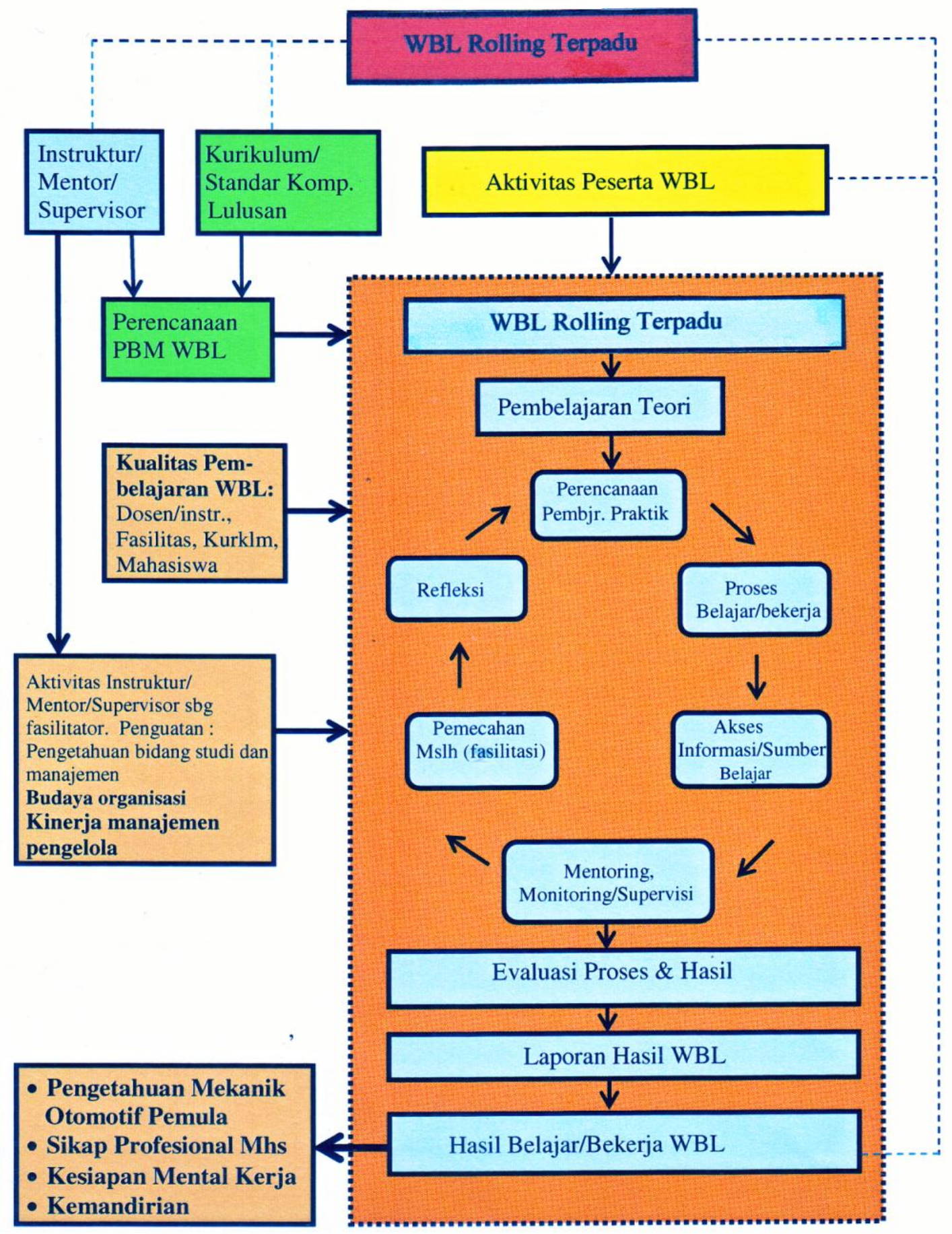

Gambar 3. Model Final WBL Rolling Terpadu 


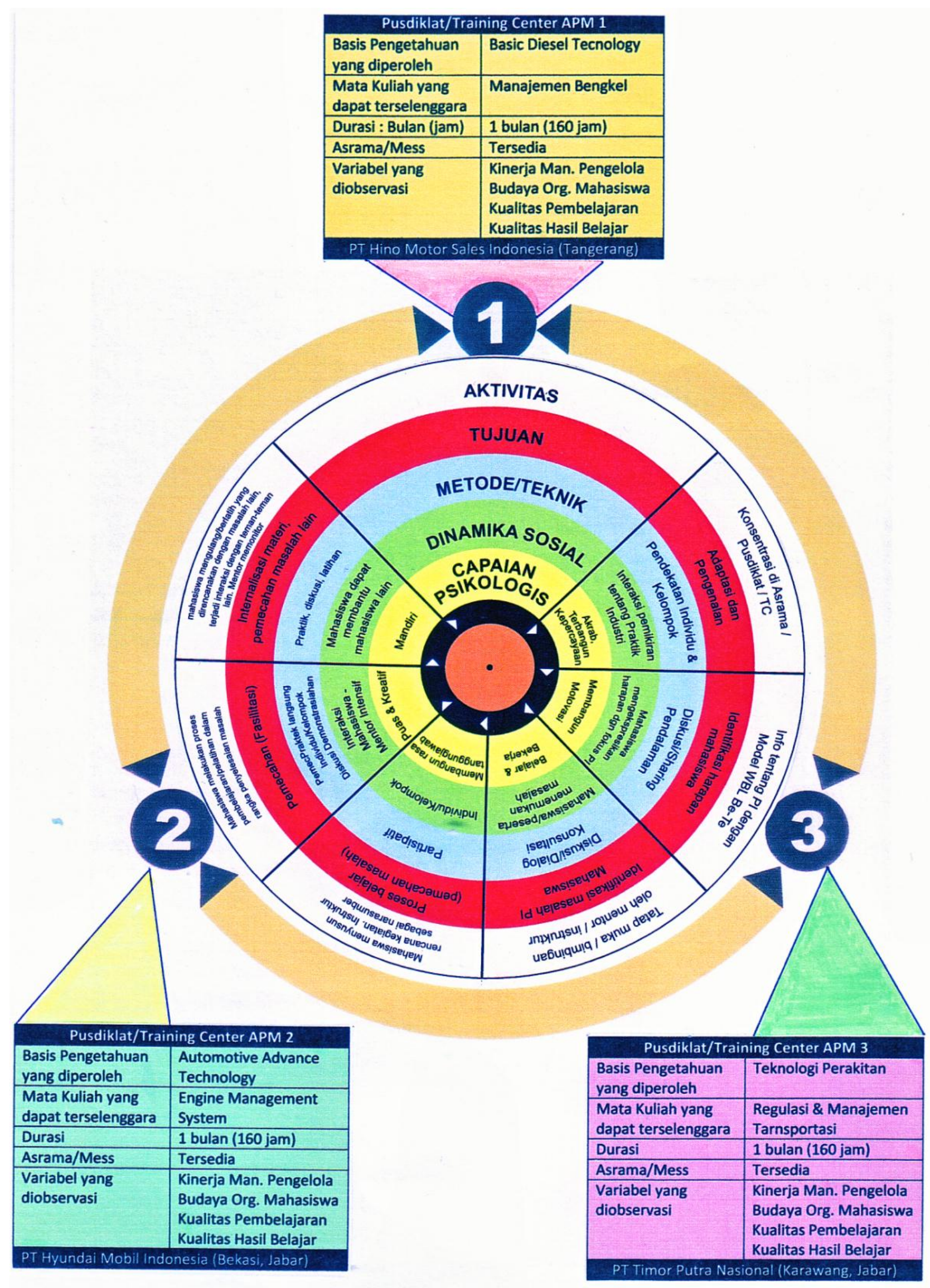

Gambar 4. Model Penyelenggaraan WBL Rolling Terpadu 


\section{KESIMPULAN}

Berdasarkan analisis data dan pem-bahasan dalam penelitian ini dapat diambil kesimpulan sebagai berikut:

1. Berdasarkan hasil uji coba dan pengembangan, model penyelenggaraan work-based learning Rolling Terpadu (RoTer) pada pendidikan vokasi Diploma III Otomotif terbukti meningkatkan kualitas hasil belajar pada program atau mata kuliah pengalaman industri yang merupakan mata kuliah lapangan pada program D-III Otomotif. Model penyelenggaraan WBL Rolling Terpadu efektif meningkatkan kualitas hasil belajar yang meliputi 4 (empat) aspek: pengetahuan mekanik otomotif, sikap profesional, kesiapan mental kerja, dan kemandirian mahasiswa.

2. Luaran (output) dari model WBL Rolling Terpadu yaitu: pengetahuan mekanik otomotif, sikap profesional, kesiapan mental kerja, dan kemandirian mahasiswa pada kelas model lebih tinggi secara signifikan dibanding kelas konvensional. Hasil uji coba model WBL Rolling Terpadu sudah memenuhi persyaratan penelitian dan pengembangan yang meliputi: akurasi, realistik, dan segi manfaat. Data dan informasi eksperimen dianalisis sesuai dengan teknik-teknik ilmiah seperti validitas dan reliabilitas instrumen, persyaratan responden, pengelompokan kelas eksperimen dan kontrol, dokumentasi, dan pemenuhan ketentuan atau persyaratan penelitian lainnya.

\section{UCAPAN TERIMA KASIH}

Pada kesempatan ini saya mengucapkan banyak terima kasih kepada para Ketua Jurusan Otomotif FT UNY, UNS, FT Unnes, Politeknik Muhammadiyah, Politek Pratama, dan UM Magelang yang telah banyak membentu pelaksanaan penelitian ini. Mudah-mudahan mendapatkan imbalan dari Tuhan Yang Masa Kuasa. Amin.

\section{DAFTAR PUSTAKA}

Bailey, T. \& Meritt, D. (1993). Youth apprenticeship : lesson from the U.S. experience. CenterFocus, 1. Diakses 8 Agustus 2008, National Center for Research in Vocational Education dari :http://ncrve.berkeley.edu/ CenterFocus/cf1.html.

Borg, W. R. \& Gall, M. D. (2003). Educational research: an introduction. Fifth edition. New York: Longman.

Bragg, D. D. (1995). Work-based learning in two-year colleges in the united states, National Center for Research in Vocational Education, Berkeley, CA. ERIC No : EDIII78446. Diakses pada tanggal 10 Pebruari 2009.

Braham, J. \& Pickering, J. (2007).Widening participation and improving economic competitiveness; the dual role of workbased learning within foundation degrees.Proceedings of The Work-based Learning Futures Conference, UK, Buxton, April 2007, 45-52.

Fallow, S., \& Weller, G. (2000). Transition from student to employee : a work-based program for "graduate apprentices" in small to medium enterprises. Journal of Vocational and Education Training, 52(4), 665-685.

Garnett, J. (2008). Recognising and enhancing the quality of university work-based learning programmes. Proceedings ofthe work-based learning futures II conference, UK, Middlesex, May 2008, 32-38. 
Gay, R. L. (1990). Educational research: competencies analysis and application. $3^{\text {rd }}$ edition. Singapore: Macmillan Pub. Co.

Glass A., Higgins, K., \& McGregor, A. (2002).Delivering work based learning.

New York: Scottish Executive Central Unit.

Gray, D. (2001). A briefing on work-based learning.Assessment Series No. 11.

Lynch, R.L. \& Harnish, D. (1998). Preparing pre-service teachers education students to used work-based strategies to improve instruction. In Contextual teaching and learning : Preparing teachers to enchance student success in the workplace and beyond (pp. 127-158). Columbus : OH : ERIC Dearinghouse on Adult, Career, and Vocational Education.

Mallika Modrakee. (2005). Vocational Education Development in a WorkBased Learning Programme.Disertasi doktor, tidak diterbitkan, School of Education Faculty of Human Development Victoria University.
Medhat, S. (2008). The path to productivity :The progress of work-based learning strategies in higher education engineering programmes. Final Report.London: The New Engineering Foundation.

Paris, K.A., \& Mason, S.A. (1995).Planning and implementing youth apprenticeship and work-based learning.Wisconsin :Center on Education and Work, Univer-sity of Wisconsin.

Raelin, J. A. (2008). Work-based learning.Bridging knowledge an action ini the workplace. New and revised Edition. San Francisco : John Wiley and Sons.

Rezin, A. A., \& McCaslin, N. L. (2001).Comparing the impact of traditional and cooperative apprenticeship programs on graduates' industri succes.Journal of Career and Technical Education, 18, Number 1 Fall.

Work-based learning guide 2002. Diakses pada tanggal 2 Pebruari 2009, dari :

http://www.iowaworkforce.org/files/wlg02.pdf 
